\title{
A INCONVENCIONALIDADE E A INCONSTITUCIONALIDADE DO MARCO TEMPORAL ESTABELECIDO SOBRE TERRAS ÍNDIGENAS PELO SUPREMO TRIBUNAL FEDERAL
}

\author{
THE INCONVENTIONALITY AND THE UNCONSTITUTIONALITY OF THE TEMPORARY \\ TIME FRAME ESTABLISHED ON INDIGENOUS LANDS BY THE SUPREME FEDERAL \\ COURT
}

\begin{abstract}
Waldir Brabo
Bacharel em Direito pelo Centro Universitário do Pará (CESUPA). Ex membro do grupo de pesquisa "Hermenêutica dos Direitos Fundamentais no Sistema Interamericano de Proteção aos Direitos Humano". Ex pesquisador voluntário no Programa de Iniciação Científica e Tecnológica do CESUPA. Estagiário da Defensoria Pública da União.

E-mail: juniorfbrabo@outlook.com
\end{abstract}

Natalia Bentes

Doutora em Direito Público pela Faculdade de Direito da Universidade de Coimbra, Portugal. Mestre em Direito pela Faculdade de Direito da Universidade do Porto, Portugal. Bacharel em Direito pela Universidade Federal do

Pará. Professora do Centro Universitário do Estado do Pará e da Escola Superior da Magistratura do Estado do Pará. Coordenadora da Clínica de Direitos Humanos do CESUPA.Coordenadora Adjunta do Curso de Direito do Centro Universitário do Estado do Pará. Advogada.

E-mail: natysimoes@ hotmail.com

Recebido em: 01/07/2019

Aprovado em: 22/09/2020

RESUMO: O presente artigo tem por objeto uma análise da inconvencionalidade e da inconstitucionalidade do marco temporal sobre terras indígenas estabelecido pelo Supremo Tribunal Federal no julgamento da Petição 3.388-4 de Roraima. Examina-se os dispositivos constitucionais, ambientais e internacionais em torno do direito dos povos indígenas à posse e à propriedade de suas terras, bem como os fundamentos históricos e socioambientais como base fundamental para a demonstração das violações dos direitos dos povos indígenas no ordenamento jurídico brasileiro. Para tanto, por meio de pesquisa bibliográfica e de seleção qualitativa de casos nacionais e das Cortes de Direitos Humanos internacionais, sustenta-se que o marco temporal é uma tese judicial incompatível com o sistema de controle convencional e constitucional das leis no ordenamento jurídico brasileiro e no sistema internacional de proteção aos direitos humanos.

Palavras-chave: Direito Internacional dos Direitos Humanos. Direito Constitucional. Marco Temporal. Povos Indígenas.

ABSTRACT: The purpose of this article is to analyze the unconventionality and unconstitutionality of the time frame on indigenous lands established by the Federal Supreme Court in the judgment of Petition 3.388-4 of Roraima. It examines constitutional, environmental and international mechanisms around the right of indigenous peoples to the possession and property of 
their lands, as well as historical and socio-environmental foundations as a fundamental basis for demonstrating violations of the rights of indigenous peoples in the Brazilian legal system. To do so, through bibliographic research and qualitative selection of national cases and the International Human Rights Courts, it is maintained that the temporal time frame is a judicial thesis incompatible with the system of conventional and constitutional control of laws in the Brazilian legal system and in the international system of protection of human rights.

Keywords: International Human Rights Law. Constitutional Law. Time frame. Indigenous Peoples.

SUMÁRIO: Introdução. 1. Perspectivas sobre a construção do conceito de dignidade dos povos indígenas na relação de ocupação com a terra pelo teóricos da Escola Ibérica da Paz. 2. As implicações jurídicas das modificações sobre o uso da terra nas colônias americanas como consequência do contato espanhol e português com o povo ameríndio. 3. Os impactos socioambientais sobre o direito originário às terras dos povos indígenas e suas atuais consequências. 4. A inconvencionalidade e a inconstitucionalidade do marco temporal no julgamento da petição 3.388 de Roraima pelo Supremo Tribunal Federal. Conclusão. Referências.

\section{INTRODUÇÃO}

A luta pelos direitos coletivos dos povos indígenas iniciou nos primórdios da colonização das coroas da Península Ibérica em face dos habitantes da América. Estabeleceuse o contato entre os povos europeus e indígenas por meio de relações de interesse econômico, com influência nos âmbitos social, cultural e ambiental, de modo a conduzir os estratagemas dos reinos ibéricos para diferentes organizações de povos indígenas com fins de atender ao objetivo de conquistar a América.

Desde então, estudiosos dos direitos dos povos indígenas criaram teorias para defender os pontos de vista antagônicos: o direito sobre a conquista e o direito dos povos indígenas como povos soberanos. Nesta discussão, o conceito sobre a dignidade do povo indígena germinou de teses que, posteriormente, deram causa ao início de um direito que viria a centralizar o ser humano, mas que tomou o rumo da centralização dos Estados e de suas consequentes relações.

Francisco de Vitória (TRINDADE, 2016) foi um dos autores a reconhecer a dignidade dos povos indígenas, dividindo racionalmente os poderes espiritual e temporal para estabelecer os parâmetros de jurisdição a serem alcançados às metrópoles europeias e às colônias. Nesse sentido, provou-se, teoricamente, a existência de autodeterminação dos povos indígenas perante o conceito de domínio sobre suas terras e seus bens e a necessidade de respeito ao modo singular de vida que cada povo apresenta.

O desenvolvimento dessas relações ensejou a gradual construção e ressignificação de um arcabouço jurídico sobre os povos indígenas que, do modelo espanhol ao modelo português, revelou um contexto de violações dos seus direitos existente até hoje. Outrossim, desde as primeiras denúncias na época da conquista, as Coroas buscaram legalizar as relações de trabalho para com os indígenas, traduzindo-se na prática em relações de exploração, tal como se observa a partir das "Leyes de Índias" e das sesmarias.

No cenário atual, encontra-se um aparato jurídico legal brasileiro e internacional robusto sobre a proteção do direito à terra, amparando a conexão peculiar dos indígenas com a terra, a relação de equilíbrio com o ecossistema local, de maneira a impactar os aspectos social, cultural e econômico das tribos existentes. Por essa razão, a Constituição Federal de 1988 apresenta uma série de dispositivos, em destaque aos artigos 231 e 225, que devem ser analisados em face dos instrumentos jurídicos internacionais sobre a proteção do meio 
ambiente, do bem-estar das populações e sua consequente relação com o direito de propriedade coletiva dos povos indígenas.

Entretanto, a partir da situação dos povos indígenas no Brasil, a exemplo das tribos em áreas de preservação ambiental, bem como da jurisprudência das Cortes Interamericana e Europeia de Direitos Humanos, percebe-se a necessidade de tutela do Estado no cumprimento das normas constitucionais, ambientais e dos documentos internacionais assinados pelo Brasil.

Diante desse contexto, o Supremo Tribunal Federal, ao realizar a tese do marco temporal, aplicando-se a todos os casos envolvendo o direito à posse indígena, apresenta uma incompatibilidade visível frente aos direitos que por ele devem ser resguardados.

Assim, o cerne da questão gira em torno do seguinte questionamento: há inconvencionalidade e/ou inconstitucionalidade na tese do marco temporal sobre terras indígenas proferida no julgamento da Petição 3.388-4 de Roraima pelo Supremo Tribunal Federal?

\section{PERSPECTIVAS SOBRE A CONSTRUÇÃO DO CONCEITO DE DIGNIDADE DOS POVOS INDÍGENAS NA RELAÇÃO DE OCUPAÇÃO COM A TERRA PELOS TEÓRICOS DA ESCOLA IBÉRICA DA PAZ}

O debate acerca do questionamento dos títulos jurídicos que legitimavam a perda do poder político e de jurisdição dos indígenas sobre seus povos influenciou diretamente na usurpação do direito de propriedade dos povos indígenas do Novo Mundo sobre seus bens e suas terras.

Neste sentido, este tema é central para a concepção de dignidade dos povos não cristãos da América pelos estudiosos da Escola Ibérica da Paz, verdadeiros teólogos catedráticos das grandes universidades ibéricas nos séculos XVI e XVII.

Explicita Silvia (2015) que muitos missionários, enviados ao Novo Mundo, foram egressos dos grandes centros universitários, carregando consigo os ideais humanitários provenientes dos conceitos cristãos, portanto, modelando as bases éticas, políticas e jurídicas sobre o processo de conquista e de colonização da América pelas consideradas metrópoles, Coroa Espanhola e Portuguesa.

É neste contexto que o conhecido autor da seara internacional à época da conquista desenvolve suas teses em uma perspectiva humanista. Nesse sentido, afastando-se da discussão em torno do título de Vitória como defensor dos direitos indígenas ou protecionista espanhol, a consolidação de seu conhecimento acerca da dignidade humana possui raízes nas linhas mestras da doutrina de São Tomás de Aquino ${ }^{1}$, de contribuição essencial para a atual compreensão de dignidade para o direito internacional.

Segundo assevera José (2016), Francisco de Vitória, após três anos de estudo em Valladolid, onde ampliou seus conhecimentos sobre a América, começou a ter contato sobre o relacionamento dos indígenas americanos com os colonizadores espanhóis por meio de notícias em Salamanca, residindo no convento de San Esteban. Esta futura universidade foi propulsão de missões de diversos frades Dominicanos ao Novo Mundo.

Diante desta trajetória, destaca-se a contribuição de contemporâneos à Vitória que defendiam a dignidade dos povos indígenas, a exemplo de Dom Bartolomeu de Las Casas. Desse modo, ao chegar na ilha caribenha Espanhola (atuais Haiti e República Dominicana), em 1502, como discípulo de Montesinos, atuou na defesa dos indígenas, tendo comparecido ao Parlamento Espanhol para manifestar sua defesa perante o Rei Carlos I (ALEIXO, 2016).

\footnotetext{
${ }^{1}$ Conforme explana José (2016), Vitória ingressou jovem na Ordem fundada por São Domingos de Gusmão, tendo estudado no Colégio de São Tiago (Saint Jacques), incorporado à Universidade de Paris, instituição na qual São Tomás de Aquino teve notável carreira de magistério.
}

Revista de Direito Brasileira | Florianópolis, SC | v. 26 | n. 10 | p. 123-143 | Mai./Ago. 2020 
Importa, a partir de sua trajetória, destacar o entrave de discussão entre o defensor dos direitos dos povos indígenas e seu opositor, Gines de Sepúlveda, no conhecido Debate de Valladolid.

Em linhas gerais, o debate envolveu, inicialmente, a tese de Sepulveda, afirmando que “a guerra justa é a necessária violência que se devia exercer para que o bárbaro se civilizasse, porque se fosse civilizado, não haveria guerra justa" (DUSSEL, 2008, p. 166, tradução nossa). Em contrapartida, a tese de las Casas destrinchou o caráter relativo sobre o conceito de bárbaro, a impossibilidade de uma guerra justa, as limitações ao Poder da Igreja, bem como a necessidade de respeitar os costumes indígenas.

Neste mesmo contexto, Francisco de Vitória, considerado o pai do direito internacional, inicia sua teoria sobre a dignidade dos povos indígenas com base na tradição de fontes Greco-romanas e medievais, porém seguindo os fundamentos na linha de pesquisa da teoria de São Tomás de Aquino. Portanto, em uma linha esquemática ${ }^{2}$, o autor segue a linha de estudo que comunica o direito divino com o direito humano, subdivididos em natural e positivo, e positivo, respectivamente. Ainda, dentro do direito positivo ${ }^{3}$, estabelece-se o estudo do direito das gentes, diferenciando-se do direito civil. ${ }^{4}$

Ressalta-se que para os teólogos da Escola Ibérica da Paz as questões indígenas deveriam ser estudadas segundo a perspectiva do direito divino natural, de modo a colocar as soberanias europeias e ameríndias no mesmo plano de igualdade a partir da noção de natureza racional e social do ser humano. Destarte, entende-se que o direito das gentes deveria ser aplicado, a partir desta ótica, da mesma forma para os povos indígenas, decorrendo do reconhecimento da condição humana, caracterizando almas racionais e com inclinações à sociabilidade por natureza cuja capacidade alcança a formação de sua própria comunidade política.

Inicia-se, com isso, a criação da noção de domínio a partir de duas perspectivas: a doutrina da propriedade, de origem Tomista, com a noção do termo originado do direito natural e a propriedade privada, originada do direito das gentes, responsável pela divisão e apropriação dos bens.

Bartolomeu de Las Casas elucida (Sílvia, 2015) que o conceito de domínio do direito natural foi modificado pelo direito das gentes, ao passo em que o domínio de jurisdição é de direito humano positivo. Dessa maneira, a Escola Ibérica da Paz considera as dicussões acerca do domínio de propriedade dos povos indígenas sobre seus bens e do domínio de jurisdição sobre o local que vivem sob a ótica do direito divino natural e do direito humano e afasta a incidência da alegação sobre a condição de infidelidade dos povos indígenas enquanto não

\footnotetext{
${ }^{2}$ Silvia relata (2015) que a concepção Tomista do Direito se sustentava na origem de Deus como causa de todas as leis. Esta ensina o homem a buscar um fim tanto no plano natural, quanto no plano sobrenatural. O ápice desta concepção é a lei eterna que passou a ser chamada de lei divina, desdobrando-se em positiva e natural. A lei divina positiva é a intervenção da vontade de Deus sobre o ser humano em sua história, para que possa ser cumprido o seu objetivo de salvação por meio da observância do Novo e Velho Testamentos. A lei natural, que também é divina, é Deus impresso no coração dos seres humanos, que são criaturas livres, racionais e que sabem a diferença entre o bem e o mal. As leis humanas positivas, por sua vez, desdobram-se em direitos das gentes e direito civil. Importante lembrar que o direito divino natural não se confunde com o direito divino positivo.

${ }^{3}$ Conforme a explanação de Fernando (2012), Francisco de Vitória, em seu comentário ao Artigo 3 da Suma Teológica de Tomás de Aquino, afirma que o direito natural trata do que é igual segundo a natureza da coisa, com base no que dispõe o Artigo 2. Entretanto, Vitoria afirma que o que é adequado a outro ou igual relativamente não se identifica com o direito natural, não é uma espécie sua e nem deriva dele. Portanto, considerando que o autor sustentou que tudo o que não é natural, é positivo, conclui Fernando que o direito das gentes só pode ser positivo, direito que resulta a partir de um estatuto humano racionalmente fixado.

${ }^{4}$ Destaca-se que, segundo Sílvia (2015), durante a linha do tempo que separa o magistério de Francisco de Vitória (século XVI em Salamanca) e de Francisco Suárez (século XVII em Coimbra), houve o aprofundamento na identificação do lugar de cada um destes ramos do Direito, aproximando mais o direito das gentes ao direito humano positivo.
} 
cristãos e pecadores mortais, pois o estado de graça ou fé nada tem a ver com a titularidade de seus domínios.

$\mathrm{O}$ autor reconhece povos indígenas como nações titulares de suas terras, partindo do pressuposto de que bárbaros índios eram verdadeiros senhores, como é apontado na tradução de sua obra De Indis com o tema "Sobre o poder civil, os índios e a guerra" (2017, p. 121).

De acordo com a sua filosofia política, o debate medieval sobre a jurisdição dos poderes espiritual e temporal tem por destaque a intermediária tese entre as conhecidas como teocrática e imperialista, defendida por João de Paris e pelo Cardeal Torquemada. Esta teoria intermediária define a clara separação entre o poder civil (temporal) e o poder eclesiástico (espiritual), distinguindo as ordens natural e sobrenatural, reconhecendo-as ambas como intrínsecas ao ser humano.

Em consequência disso, permite-se esclarecer que ao Papa é reconhecido o devido poder espiritual no que tange os fins sobrenatural e de administração das coisas espirituais, restando-lhe o cuidado sobre os cristãos, ou seja, sem qualquer poder sobre os infiéis da América segundo a Escola Ibérica da Paz. Além disso, tendo o domínio sobre o poder espiritual, cabia-lhe agir indiretamente por meio dos reis ibéricos, porém sem realizar determinações ou concessões diretas, pois não lhe havia legitimidade para tanto. Desse modo, observa-se a falta de legitimidade para o próprio desrespeito à soberania indígena, sem qualquer justificação plausível em termos de guerra justa ou de escravidão.

Imperiosos foram os dicursos de Bartolomeu de Las Casas no reforço à proibição da submissão dos povos indígenas a qualquer outro povo e de Francisco de Vitória partindo da asserção da ideia de igualdade humana com reflexão para a atual realidade. Com isso, conforme Augusto (2016) esclarece, na era dos tribunais internacionais a jurisdição internacional se mostra como última esperança para os esquecidos e marginalizados das jurisdições nacionais, de acordo com o seu voto no julgamento do mérito do caso da Comunidade Moiwana versus Suriname. Dessa maneira, Vitória cria a concepção de povos constituídos como comunidades independentes, perfeitas, ensejando a denominação do termo jus inter gentes, de maneira que todos estes povos, com reconhecimento mútuo, devem respeitar o direito internacional, este "conjunto de leis equânimes que regulam a relação entre os povos, não sendo permitido a um povo individualmente furtar-se ao seu cumprimento." (OLIVEIRA, 1969, p. 376).

Tanto Francisco Suárez quanto Francisco de Vitória sustentaram a igualdade entre as nações nos mesmos termos para os indivíduos, destacando a justiça, a boa fé e a igualdade como bases para a relação de uma verdadeira comunidade internacional. O pensamento de Suárez sobre a comunidade universal é diametralmente oposto aos interesses estatais, acostumados com a autotutela, caracterizadora de soberanias individuais e que conectam-se apenas por interesses geopolíticos. $\mathrm{O}$ verdadeiro conceito de comunidade universal para o autor pode ser descrito pelas palavras de Pedro Calafate (2017, p. 6):

A exigência de consideração do plano universal e da consequente unidade e direitos do género humano como um todo, conduzia à necessidade de racionalizar a guerra, entendendo que a guerra não era um meio natural de resolução de conflitos e afirmando a paz como caracterização da vida. Ou seja, nas matérias tão relevantes da paz e da guerra, não cumpria atender apenas ao interesse particular do estado, mas sim vincar a precedência e primazia ontológica da razão da humanidade sobre a razão de estado, do amor mútuo sobre a soberania e ainda da consciência sobre a vontade.

Assim sendo, Vitoria e Suárez, em uma perspectiva jusnaturalista, fundando-se na ideia de universalidade de um direito natural entre os estados, buscou reconhecer a dignidade dos 
indígenas, mostrando que são detentores de direitos e formadores de comunidades soberanas e independentes. A cada indígena, seres dotados de racionalidade tais como os castelhanos são, é reconhecido o domínio sobre o uso de suas terras, utilizando-se de suas faculdades racionais para estabelecer o seu modo de vida, peculiar a cada ser humano, encerrando em si dignidade por essência.

\section{AS IMPLICAÇÕES JURÍDICAS DAS MODIFICAÇÕES SOBRE O USO DA TERRA NAS COLÔNIAS AMERICANAS COMO CONSEQUÊNCIA DO CONTATO ESPANHOL E PORTUGUÊS COM O POVO AMERÍNDIO}

Desde tempos remotos, nações indígenas habitantes da América compartilhavam noções diversas do conceito de territorialidade de fronteiras como é atualmente conhecido. Tratava-se de afinidade ancestral, costumes, parentesco e religiões comuns. Outrossim, devido a essa diversidade de Povos da América Latina, a ideia de território "é fundada em mitos, crenças e cultura, fazendo com que os critérios da própria ocupação e da defesa contra a ocupação por terceiros sejam diferentes" (FILHO, Carlos, 2006, p. 43).

Em contraste com a ideia de selvageria, de violência e de falta de humanidade que se tinha na Europa antes do contato com os povos originários da América, o Escriba, Pêro Vaz de Caminha, após o contato inicial dos portugueses com os habitantes do Brasil, demonstra admiração com a limpeza, com a saúde e com a beleza dos indígenas, tendo tirado suas conclusões por meio de observações, como se verifica:

"Parece-me gente de tal inocência que, se homem os entendesse e eles a nós, seriam logo cristãos, porque eles, segundo parece, não têm, nem entendem em nenhuma crença.

E portanto, se os degredados, que aqui hão-de ficar, aprenderem bem a sua fala e os entenderem, não duvido que eles, segundo a santa intenção de Vossa Alteza, se hão-de fazer cristãos e crer em nossa santa fé, à qual praza a Nosso Senhor que os traga, porque, certo, esta gente é boa e de boa simplicidade. E imprirmir-se-á ligeiramente neles qualquer cunho que lhes quiserem dar (...)."

Diante dos relatos dos escribas, percebe-se a repetição dos comentários sobre a beleza, a mansidão dos indígenas e a quantidade de gente encontrada, das quais conclui-se que nunca houve, tecnicamente, a ideia de terra desabitada.

Interessante destacar que dos relatos dos primeiros cronistas não consta a ideia de organização social e de crença destes povos, porém é perceptível que estas análises necessitem de um contato prolongado com os seus costumes e com o seu arcabouço cultural. Inclusive, eram considerados povos, de início, sem Deus e sem Lei, afastando-se a possibilidade de haver um Direito Interno regulamentando as suas relações.

A visão de Colombo, em suas cartas ao rei de Espanha, demonstra a generosidade dos povos da América Central, a exemplo do relato de um grupo de indígenas que o ajudou a desencalhar uma nau voluntariamente, organizados sob a chefia de um poderoso líder 5 . Entretanto, o reconhecimento do escrivão não se realizou suficiente para impedir que alguns

\footnotetext{
${ }^{5}$ Segundo Carlos (apud OLIVA DE COLL, 1986, p. 13), tal foi a presteza, gentileza e severidade do trabalho, que Colombo escreveu: "Certifico a Vossa Alteza que em nenhuma parte de Castela se colocaria tanto cuidado em todas as coisas, a ponto de se poder dizer que não faltou sequer uma agulha que fosse. (...) Acredito que não exista no mundo melhor gente e melhor terra".
}

Revista de Direito Brasileira | Florianópolis, SC | v. 26 | n. 10 | p. 123-143 | Mai./Ago. 2020 
indígenas fossem levados para a Espanha, onde foram intitulados como escravos, sendo utilizados como coletores de ouro para acumular as riquezas da metrópole espanhola.

Doravante, a Espanha foi capaz de produzir um sistema jurídico robusto para as suas colônias, conhecido como derecho indiano: um verdadeiro conjunto de normas com vigência sobre as Índias no período colonial.

O sistema jurídico do direito indiano foi destinado às Américas, tendo sido caracterizado pelas marcas do período feudal europeu, dotado de diversas províncias e suas inúmeras diferenças locais, portanto, todo o arcabouço jurídico importado do período feudal foi posto sobre a diversidade existente na vida indígena Americana. Tal contexto resultou nas diversas incongruências de um sistema jurídico que não retratava a realidade do novo continente para os europeus.

Destaca-se, com isso, alguns dos institutos manejados pela metrópole espanhola, cuja importância revela as posteriores configurações jurídicas em torno da vida dos povos indígenas na América.

O primeiro deles tem como marco a edição das Leyes Nuevas por Carlos V, em 1542, as quais, segundo afirma Deise Christina Schell (2010, p. 28), "foi a forma que a coroa encontrou para pôr fim aos privilégios dos conquistadores, diminuindo, assim, o grau de controle pelos encomenderos".

Explica-se as Leyes Nuevas pelas palavras de Felipe Salustino (2013, p. 29):

Estas leis foram os primeiros regulamentos que regiam o comportamento dos colonos espanhóis na América, especialmente no que diz respeito ao trato com os índios. Nelas continham regras enumeradas para o governo dos povos indígenas no Novo Mundo, como: o suprimento de comidas, roupa e de camas para os índios, proibição aos maus-tratos e apoiava sua conversão ao catolicismo. Ordenavam que os espanhóis os utilizassem na construção de igrejas e lhes ensinassem a doutrina cristã e que batizassem os filhos indígenas (...).

Destarte a edição das Leis, o sistema de encomenda ${ }^{6}$ passou da primeira fase, representada pela servidão, para uma fase marcada pela isenção tributária, na qual a coroa utiliza o sistema econômico dos principais povos americanos, o qual está fundado na lógica da tributação das castas ou dos povos. Desse modo, o "encomendeiro" lidava diretamente com a dinâmica tributária do sistema de exploração ${ }^{7}$, estando responsável pelo cumprimento legal de condutas minimamente regulamentadas pela coroa. Logo, compreende-se o sucesso desta forma de conquista para as regiões em que predominava uma organização indígena própria ao sistema tributário adotado, categorizando esta forma particular de dominação.

Por outro lado, outros contextos de dominação revelam diferentes cenários, de maneira que as legislações poderiam ser adotadas conforme a lógica peculiar de ocupação e de dominação do povo indígena. A exemplo, relata Carlos (2006) que na atual Colômbia, os muíscas ou chibchas foram levados ao extermínio, mesmo tendo excelente organização tributária e ourives. Tal povo detinha organização suficiente para regulamentar um direito de família e designar contratos de compra e venda, além de suas próprias sanções penais.

\footnotetext{
${ }^{6}$ Segundo Deise Christina Schell (apud Bethell, História da América Latina, p. 274) a partir da primeira década do século XVI a prática de repartir os nativos e cercear sua liberdade se desenvolveu sob a forma de uma instituição tradicional e reguladora do trabalho conhecida como a "encomienda", ou "repartimiento".

${ }^{7}$ Segundo Waldir e Natalia (2018), nesta prática, familiares de indígenas em grupos, com seus próprios caciques, eram submetidos à autoridade de um espanhol chamado de "encomedero". Os colonos responsáveis por cada grupo possuíam duas tarefas: a proteção dos indígenas e a sua cristianização.
}

Revista de Direito Brasileira | Florianópolis, SC | v. 26 | n. 10 | p. 123-143 | Mai./Ago. 2020 
As Ordenações do Reino de Portugal, divergindo da Coroa Espanhola, adaptaram a sua própria legislação por meio de "mutação não explícita de interpretação" (FILHO, Carlos, p. 53), a exemplo das sesmarias.

Segundo Beatriz Perrone-Moisés (1999, p. 2-3),

A legislação portuguesa para a Colônia brasileira consagra, desde o século XVI, os direitos dos povos indígenas a seus territórios. Em Alvará de 1596, referindo-se às terras dos índios nos aldeamentos localizados junto às povoações coloniais, lê-se: "o gentio [...] será senhor de sua fazenda, asi como o he na serra". Sob a formulação "senhores de suas terras nas aldeias como o são na serra" reconhecimento cristalino de direitos territoriais anteriores à colonização e, independentes dela, a afirmação seria retomada nas Leis de 1609 e 1611, que constituem marcos na legislação indigenista colonial, e, com algumas variações, em vários documentos legais posteriores. Reconhecidos os direitos legais e históricos, como diríamos hoje, dos povos indígenas às suas terras, durante toda a colonização não houve um momento sequer em que esse princípio fosse expressamente negado ou restrito.

Visto que a legislação portuguesa da época proibia a escravização de indígenas, entende-se que houve uma série de ilegalidades, praticadas com frequência, pois havia a permissão para sua prisão em cativeiro somente nos casos de guerra justa ou no caso dos salteadores ou fugitivos (SOUZA, 1998).

Ressalta-se que houve extrema dificuldade para os portugueses em manter o trabalho dos nativos americanos que, devido às condições de semi-escravidão impostas nos trabalhos da lavoura, fugiam para as montanhas ou para dentro das florestas, com contatos que tinham de outras tribos ou de parentes e pelo conhecimento geográfico da região.

A legislação portuguesa da época colonial proibia a escravidão dos indígenas, porém regulamentava a sua exploração de mão de obra para o trabalho, segundo o seu ponto de vista, produtivo, de modo a atender aos interesses da colonização.

Ademais, observa-se que dispositivos legais da época, tais como Alvarás do rei de Portugal, revelam a produção normativa com o ponto de vista do colonizador, mesmo que com a intenção de regulamentar a relação dos europeus no trato com os povos indígenas.

Assim é a leitura de um Alvará expedido pelo rei de Portugal:

"Eu ei Rey faço saber aos que este Alvará virem que eu sou informado que será muito serviço de deos e meu e em prol e beneficio das fazendas e engenhos de meus vassalos das partes do brazil darem se terras de sesmaria ao gentio que decer do sertão pera faserem suas lavouras, e que será isto meio pera decerem muitos e virem mais depressa no conhecimento de nossa santa fee e receberem o santo batismo, [...]" (PERRONE MOISÉS, Beatriz, 1998, p. 113)."

Percebe-se, então, que não há uma valorização da pessoa indígena, mas a descrição e determinação de uma utilização e verdadeira imposição de conduta, limitando garantias de direito alheio ao português. Portanto, como afirma Carlos Filho (2006, p. 55), “(...) a única preocupação dos colonizadores para com os indígenas era a integração destes na nova sociedade."

Finalmente, faz-se de essencial contribuição a menção às sesmarias. No reino de Portugal, este Instituto foi aplicado para terras que haviam sido exploradas e lavradas, porém estavam inférteis, improdutivas e abandonadas. Nesse sentido, com o objetivo de desenvolver

Revista de Direito Brasileira | Florianópolis, SC | v. 26 | n. 10 | p. 123-143 | Mai./Ago. 2020 
economicamente, D. Fernando, em 1375, criou por Lei este Instituto para todos transformarem suas terras em lavradio, sob pena de a perderem para famílias produtivas, tendo sido reestruturadas em 1514 pelas Ordenações Manuelinas e repetidas em 1789 pelas Ordenações Filipinas.

Por outro lado, no Brasil, as sesmarias foram produzidas em terras ocupadas pelos povos indígenas, os quais mantinham um sistema de rotatividade sobre o cultivo de plantações e demais recursos naturais, mantendo a regeneração da floresta. Devido a isso, o verdadeiro sentido das sesmarias no Brasil foi de instrumento de conquista, desrespeitando qualquer tipo de uso indígena.

O Instituto gerou problemas fundiários pela falta de respeito à regulamentação jurídica sobre as medições, demarcações, plantações e ocupações, pois deveriam ter todos estes requisitos atendidos para serem legalmente válidas ao reino de Portugal, resultando, com as frequentes ilegalidades, na contemporânea consolidação do latifúndio, cujos impactos afetam diretamente a vida dos povos indígenas até os atuais dias.

\section{OS IMPACTOS SÓCIOAMBIENTAIS SOBRE O DIREITO ORIGINÁRIO ÀS TERRAS DOS POVOS INDÍGENAS E SUAS ATUAIS CONSEQUÊNCIAS}

No Brasil, estima-se que há pelo menos 5 mil povos indígenas com 274 variantes linguísticas (IWGIA, 2015). Mais de 50 por cento desta população vive nas chamadas Terras Indígenas, correspondendo, em relação ao total de habitantes brasileiros, menos de 1 por cento.

Segundo Darcy Ribeiro (1996), nos moldes atuais do país, as populações indígenas podem ser classificadas em quatro diferentes categorias em relação ao grau de contato com a sociedade nacional, sendo estes: isolados, de contato intermitente, de contato permanente e integrados.

A primeira categoria tem como consequência tribos com completa autonomia cultural, vigor físico e número de população maior em relação às tribos de outras categorias. Estes são os isolados, grupos que vivem nas zonas não alcançadas pela sociedade brasileira, com raríssimos contatos acidentais.

A segunda categoria corresponde aos grupos inicialmente afetados pelo contato da ocupação e do alcance da sociedade nacional. Apesar de ainda possuírem certa autonomia cultural, demonstram a necessidade de estabelecer relações econômicas com não indígenas, compreendendo uma certa diversificação de suas tarefas habituais.

A terceira categoria demonstra perda completa da autonomia sociocultural, tornandose dependente da economia regional por meio de artigos indispensáveis. Esta categoria, a de contato permanente, conserva costumes tradicionais com modificações dos efeitos econômicos, culturais e ecológicos. Aumenta-se o meio de comunicação pela maior quantidade de indígenas a falar a língua portuguesa, com a consequente diminuição do número de membros da população.

A quarta, e última, categoria exprime a população indígena que sofreu todos os efeitos anteriores, conseguindo sobreviver em meio à produção nacional como mão-de-obra ou como produtores especializados em artigos para o comércio. Darcy (1996) afirma que suas residências são parcelas de seus antigos territórios ou simplesmente não fixas, bem como sua aparência se transformou a ponto de serem confundidos com os neobrasileiros ${ }^{8}$, mantendo sua identidade étnica apenas por seu sentimento de pertencimento como povo constituído.

\footnotetext{
${ }^{8} \mathrm{O}$ autor Raimundo Giarola (2012, p. 132) explicita que, [...]Ribeiro acredita em uma miscigenação mais intensa e mais importante entre brancos e índios, seja no plano biológico, seja no plano cultural. O mameluco é o grande cerne da nacionalidade, enquanto o negro, e em consequência seus descendentes, perde sua cultura ao ser inserido como escravo na colônia. Por isso, Darcy Ribeiro afirma que os neobrasileiros, primeiros habitantes dos núcleos coloniais, possuíam feições indígenas.
}

Revista de Direito Brasileira | Florianópolis, SC | v. 26 | n. 10 | p. 123-143 | Mai./Ago. 2020 
Observa-se que até os dias atuais as populações indígenas encontram-se nas categorias mencionadas, de modo que a influência do contato com a sociedade nacional brasileira ainda prova efeitos com interferência no desenvolvimento econômico, social e cultural do indígena 9 . Deve-se, com isso, atentar ao caput do artigo 231 da Constituição Federal, tal como estabelece, in verbis:

Art. 231. São reconhecidos aos índios sua organização social, costumes, línguas, crenças e tradições, e os direitos originários sobre as terras que tradicionalmente ocupam, competindo à União demarcá-las, proteger e fazer respeitar todos os seus bens. (PRESIDÊNCIA DA REPÚBLICA, 1988).

À vista disso, é constitucionalmente previsto o direito à diferença aplicado aos povos indígenas, devendo o Estado Brasileiro respeitar o modo de viver indígena perante os seus costumes, tradições e especialmente a relação desses elementos com a terra que ocupam. Nesse sentido, os instrumentos jurídicos se fazem fundamentais para a garantia dos direitos desses povos frente as violações acometidas, em particular as próprias instituições responsáveis pela sua proteção.

Os direitos dos povos indígenas estão intimamente relacionados com o Direito ambiental e com os instrumentos de eficácia dos direitos fundamentais que consolidam a área do Direito Internacional dos Direitos Humanos. O exame das normas internacionais coadunadas com as internas do ordenamento jurídico brasileiro é necessário, visto que a própria visão ecológica sobrevive a partir da subsistência de relações inclusivas.

Neste contexto, anteriormente à Constituição Federal de 1988, a ideia de criar grandes áreas ambientais protegidas no século XIX foi justificada por questões como proveito econômico, saúde pública, proteção de recursos hídricos e o destaque ao reconhecimento sobre o valor estético e cultural relacionado à natureza. Cançado (2017) afirma que a noção de vida natural e selvagem foi criada nos Estados Unidos da América, ao final do século XIX, visando a impossibilidade de expansão das áreas agrícolas para que a população urbana tivesse o direito ao lazer e à recreação, visto que naquele país houve o extermínio dos povos indígenas. Como resultado, o autor explicita a criação do Hot Springs National Park (1832), do Yosemite National Park (1864) e do Yellowstone National Park (1872).

Esse movimento, conhecido como conservacionista ${ }^{10}$, fundamentou a exigência de proteção especial, desenvolvendo valores e práticas ecológicas com o escopo de manutenção da diversidade genética de determinados ecossistemas e áreas ambientais.

Em âmbito brasileiro, as práticas do movimento conservacionista entraram em processo de internalização jurídica no século XX. Destaca-se a criação do Parque Nacional do Xingu, pelo Decreto n ${ }^{\circ} 50.455$, de 14/04/1961, assinado pelo Presidente Jânio Quadros, tendo sido inicialmente regulamentado pelo Decreto ${ }^{\circ} 51.084$, de 31/07/1961.

O Parque Nacional, em seu primórdio, foi criado como uma categoria híbrida, devendose ao duplo propósito de proteção ambiental e das populações indígenas ao passo em que se submetia à fiscalização do órgão indigenista (SPI - Serviço de Proteção aos índios) e do órgão

\footnotetext{
${ }^{9}$ O Brasil é signatário do Pacto Internacional sobre os Direitos Econômicos, Sociais e Culturais que exprime, em seu artigo $1^{\circ}$ (1) o direito de todos os povos à autodeterminação e, em decorrência desse direito, terem a liberdade de assegurar o seu próprio estatuto, bem como conduzir o seu desenvolvimento econômico, social e cultural.

${ }^{10}$ Importante esclarecer que o movimento conservacionista é mais consciente, exaltando o amor à natureza e ao meio ambiente aliado ao uso racional de matéria-prima e bens naturais. Com isso, os seres se percebem como partes integrantes do mundo ecológico, modo de pensar que é muitas vezes visto como o meio termo entre o preservacionismo e o desenvolvimento capitalista inicial.
} 
ambiental. Após a criação da FUNAI (Fundação Nacional do Índio) ${ }^{11}$, o Parque Nacional passou a ser designado como Parque Indígena, destinando-se à proteção da socio diversidade nativa.

Importa salientar que o Parque Indígena possui tribos de diversas etnias, dentre as quais cita-se os Trumai, os Ikpeng e os Kaiabi, do médio Xingu (ISA, 2018). Cada uma dessas tribos possui uma história de resistência e faz parte de uma pequena porcentagem de tribos que estão em área de preservação ambiental.

Nas décadas de 80 e de 90, as tribos do Parque Indígena sofreram invasões de pescadores e caçadores, além da ameaça de queimadas de fazendas pecuárias e o avanço de madeireiras que chegaram próximo aos limites físicos da demarcação do Parque. Por essa razão, as tribos se organizaram para garantir novos pleitos territoriais. Este é o caso dos Ikpeng que se articulam para reivindicar parte de seu território tradicional na região do Rio Jatobá, que ficou fora da demarcação do Parque. ${ }^{12}$

Diante do contexto exposto, explana-se que o advento da Magna Carta de 1988 trouxe a regulamentação constitucional destes espaços, dispondo no caput do artigo 225 o que segue:

Art. 225. Todos têm direito ao meio ambiente ecologicamente equilibrado, bem de uso comum do povo e essencial à sadia qualidade de vida, impondose ao Poder Público e à coletividade o dever de defendê-lo e preservá-lo para as presentes e futuras gerações. (PRESIDÊNCIA DA REPÚBLICA, 1988).

Nota-se a presença implícita do princípio da solidariedade intergeracional como diretriz do sistema jurídico no sentido de racionalizar o uso dos recursos naturais, tornando-os sustentáveis à medida que as próximas gerações possam manter ou aumentar o seu padrão de qualidade de vida. Conseguintemente, observa-se que a Magna Carta brasileira reconheceu a multietnicidade e a pluralidade cultural existente no País, assegurando aos indígenas o direito de serem tratados como diferentes da sociedade nacional.

Além disso, é possível inferir do artigo 225 da Constituição Federal a conexão entre a tutela do meio ambiente e a proteção da pessoa humana, sendo obrigação do Estado manter a qualidade de vida para proteger a saúde, o bem-estar e a segurança da população.

Em uma interpretação sistemática, tal entendimento é encontrado em sentença da Corte Europeia dos Direitos do Homem, no julgamento do caso Di Sarno e outros Vs. Italia, no qual houve o reconhecimento pelo Tribunal da violação ao direito à vida como resultado dos danos causados ao meio ambiente local em razão da falta de implementação de políticas públicas para a coleta de lixo público, tratamento e disposição do serviço. A apresentação do caso foi realizada por 18 cidadãos italianos que trabalhavam na Comuna de Somma Vesuviana, em Campania, oportunidade em que alegaram violação ao artigo $2^{\circ}$ da Convenção Europeia de Direitos do Homem. A Segunda Seção entendeu pela procedência do pedido em violação ao direito à vida, condenando o Estado italiano a obrigação de pagar em forma de indenização pela demora prolongada na adequada prestação do serviço e pelos danos ao meio ambiente, e consequentemente à vida, que essa omissão causou.

\footnotetext{
${ }^{11}$ Somente em 1967, substituindo o SPI, foi criada a FUNAI (Fundação Nacional do Índio). Ressalta-se que em 2019 a competência da FUNAI para a identificação, delimitação e demarcação de terras tradicionalmente indígenas foi transferida para o Ministério da Agricultura, Pecuária e Abastecimento. Apesar disso, o Partido Socialista Brasileiro propôs Ação Direta de Inconstitucionalidade contra o inciso XIV, do artigo 21 da Medida Provisória $\mathrm{n}^{\circ} 870 / 2019$, bem como contra o $\$ 2^{\circ}$ do referido artigo.

${ }^{12}$ Em 2019, o atual cenário do Parque Indígena do Xingu revela ameaças ainda maiores à integridade do território demarcado, de modo que o líder indígena brasileiro Raoni Mertuktire, realizando turnê na Europa para reivindicar ajuda internacional, alerta para ameaça de grandes fazendas e do desmatamento.
} 
Sobre o tema, a Opinião Consultiva ${ }^{\circ} 23$ de 2017, levantada pela Colômbia em face à Corte Interamericana de Direitos Humanos diz respeito a diversos aspectos relacionados às obrigações dos Estado em respeitar e garantir os direitos humanos e ao meio ambiente. Em seu parágrafo 48, a OC 23-17 revela que em casos de direitos territoriais dos povos indígenas e tribais, o Tribunal se refere à relação entre um meio ambiente sadio e adequado à proteção dos direitos humanos, considerando que o direito à propriedade coletiva está vinculado com o acesso aos recursos que se encontram nos territórios dos povos, pois estes recursos naturais são necessários para a sobrevivência, desenvolvimento e continuidade em seu estilo de vida.

Imprescindível mencionar a Declaração sobre o Direito ao Desenvolvimento das Nações Unidas de 1986 que, em seu artigo $1^{\circ}$, estabelece o direito ao desenvolvimento como direito humano inalienável. Outrossim, os parágrafos 1 e 2 expõe o direito à participação de todos os povos no desenvolvimento econômico, social e cultural e sua direta relação com a autodeterminação dos povos, garantindo a soberania sobre riquezas e recursos naturais, destacando os Pactos Internacionais, ambos ratificados pelo Estado brasileiro.

Assente nisso, constata-se a real necessidade da tutela do meio ambiente em face à proteção dos grupos minoritários e vulneráveis, tais como os povos indígenas.

Sobre o assunto, Antônio Augusto Cançado Trindade (1993, págs. 110-111) conceitua e adverte:

O conceito de desenvolvimento humano avançado pelo PNUD ${ }^{13}$ tem implicações diretas para a questão ambiental, como adverte o PNUD, a pobreza é uma das maiores ameaças ao meio ambiente e à própria sustentabilidade da vida humana. Não é por causalidade que "quase todos os pobres vivem nas áreas vulneráveis do ponto de vista ecológico": $80 \%$ dos pobres na América Latina, $60 \%$ dos pobres na Ásia e 50\% dos pobres na África vivem em "terras marginais caracterizadas por uma baixa produtividade e uma alta susceptibilidade à degradação ambiental” (...).

Portanto, importante se faz realizar a análise da tutela ambiental por intermédio dos parágrafos do artigo 231 combinados com os parágrafos do artigo 225 da Constituição Federal, os quais abrangem os princípios da prevenção, da precaução e da informação ambiental que se relacionam com o direito ao reconhecimento dos direitos originários dos indígenas sobre suas terras, cabendo-lhes a posse permanente e assegurando-lhes o usufruto exclusivo das riquezas do solo e dos lagos nela existentes ( $\$ 2^{\circ}$, artigo 231, Constituição Federal de 1988).

Além desses dispositivos, pode-se expandir a interpretação legal mediante o que estabelece o Estatuto do Índio (Lei n. 600/71), dispondo sobre as ações de proteção ambiental, saúde e apoio às atividades produtivas para as comunidades indígenas. Com isso, para preservação dos direitos das comunidades indígenas, o caput do artigo $2^{\circ}$ do Estatuto prevê a competência dos entes federativos, com exclusão do Distrito Federal, na proteção das comunidades indígenas e preservação de seus direitos, destacando-se os incisos III, V e IX, como se lê:

III - respeitar, ao proporcionar aos índios meios para o seu desenvolvimento, as peculiaridades inerentes à sua condição;

$\mathrm{V}$ - garantir aos índios a permanência voluntária no seu habitat, proporcionando-lhes ali recursos para seu desenvolvimento e progresso;

IX - garantir aos índios e comunidades indígenas, nos termos da Constituição, a posse permanente das terras que habitam, reconhecendo-lhes o direito ao

${ }^{13}$ Programa das Nações Unidas para o Desenvolvimento.

Revista de Direito Brasileira | Florianópolis, SC | v. 26 | n. 10 | p. 123-143 | Mai./Ago. 2020 
usufruto exclusivo das riquezas naturais e de todas as utilidades naquelas terras existentes; (PRESIDÊNCIA DA REPÚBLICA, 1973).

O artigo 24 do mesmo Estatuto compreende expressamente o direito de posse, como se verifica:

Art. 24. O usufruto assegurado aos índios ou silvícolas compreende o direito à posse, uso e percepção das riquezas naturais e de todas as utilidades existentes nas terras ocupadas, bem assim ao produto da exploração econômica de tais riquezas naturais e utilidades (PRESIDÊNCIA DA REPÚBLICA, 1973).

O dispositivo do Estatuto do Índio deve ser lido à luz da Convenção 169 da Organização Internacional do Trabalho sobre Povos Indígenas e Tribais, para a qual o direito de usufruto das terras significa subsistência com dignidade, devendo o Estado garantir os procedimentos adequados para a manutenção deste direito. De tal modo, a Convenção, em seu artigo 14, itens 1,2 e 3, estabelece que o governo deve adotar medidas para salvaguardar o direito dos povos interessados em utilizar as terras tradicionalmente ocupadas, assim como a sua reivindicação

Ambos instrumentos jurídicos estão de acordo com o exposto no parágrafo segundo do artigo 231 da Constituição Federal acerca do direito originário às terras indígenas, bem como se deve frisar o parágrafo quarto do artigo, de acordo com o que se lê:

$\S 4^{\circ}$ As terras de que trata este artigo são inalienáveis e indisponíveis, e os direitos sobre elas, imprescritíveis (PRESIDÊNCIA DA REPÚBLICA, 1988).

Diante do contexto legal apresentado, compreende-se o verdadeiro mundo jurídico necessário à proteção dos direitos dos povos indígenas, que nos atuais dias ainda apresenta uma série de dificuldades a serem respeitados e mantidos de acordo com o texto dos instrumentos legais.

\section{A INCONVENCIONALIDADE E A INCONSTITUCIONALIDADE DO MARCO TEMPORAL NO JULGAMENTO DA PETIÇÃO 3.388 DE RORAIMA PELO SUPREMO TRIBUNAL FEDERAL}

No que concerne o duplo controle vertical de juridicidade aplicado aos direitos à posse de terras ocupadas por povos indígenas no território brasileiro, percebe-se a incongruência do entendimento do Supremo Tribunal Federal no julgamento Petição 3.388-4 de Roraima quando estabelece um marco temporal para decidir sobre o direito à propriedade coletiva dos povos indígenas, verificando-se, com base nas teses dos primeiros estudiosos sobre as questões indígenas para o reconhecimento de sua dignidade e de sua soberania, bem como o contato histórico da relação de exploração vivida por milhares de indígenas, a violação de dispositivos constitucionais e dos tratados de direitos humanos vigentes no país.

O caso iniciou por uma Ação Popular proposta pelo Senador Augusto Affonso Botelho Neto (PT) juntamente com o Senador Francisco Mozarildo de Melo Cavalcanti (PTB), no ano de 2005, em face da União, com o objetivo de suspender a Portaria 534/2005 e no mérito declará-la inconstitucional. Tal portaria foi homologada pelo Decreto Presidencial de Revista de Direito Brasileira | Florianópolis, SC | v. 26 | n. 10 | p. 123-143 | Mai./Ago. 2020 
15.04.2005 que demarcou administrativamente a Terra Indígena Raposa Serra do Sol, determinando a posse das terras aos grupos indígenas Ingarikó, Makuxi, Patamona, Taurepang e Wapixana.

Em síntese, o requerente alegava haver vícios no processo administrativo de demarcação, não tendo sido respeitado o Decreto $\mathrm{n}^{\circ}$ 1.775/1996. Esta demarcação de área contínua resultaria em desastrosas consequências para o Estado de Roraima no que tange a economia, afetando a vida da população não indígena, portanto, afirma que a situação constitui violação ao princípio da razoabilidade por privilegiar a tutela indígena sobre a livre iniciativa (Trecanni, Alves, 2017).

A União, na contestação, apresentou levantamento histórico de ocupação indígena no local, demonstrando a legislação aplicável à questão do período colonial aos dias atuais. Com base no artigo 231 da Constituição Federal de 1988, afirmou não ter havido lesão ao patrimônio público, de modo que o autor da ação não provou suficientemente os vícios no processo administrativo de demarcação.

$\mathrm{Na}$ decisão, foram fixados dezoito parâmetros ou condições para considerar uma terra como indígena tradicional. Dentre elas, encontra-se a tese do marco temporal, a qual, em síntese, estabelece que a Constituição trabalha com data certa como referencial para verificar a ocupação de um determinado espaço geográfico por uma etnia aborígene, ou seja, para o reconhecimento dos direitos originários sobre as terras que tradicionalmente são ocupadas por indígenas.

Nesta linha de raciocínio, a decisão revela que a tradicionalidade da posse nativa é proveniente do caráter de perdurabilidade, não se perdendo por uma reocupação que não ocorreu por efeito de renitente esbulho por parte de não-índios.

Destaca-se o posicionamento do Relator Ministro Ayres Britto, declarando que já há coordenadas jurídicas na Constituição Federal para identificação de terras objeto de demarcação sem a antagonia entre o reconhecimento deste direito originário e o desenvolvimento nacional. Outrossim, no tocante à tese do marco temporal da ocupação, o ministro aponta que a Magna Carta estabeleceu data certa como referencial para o reconhecimento do território indígena, a data de sua promulgação (5 de outubro de 1988), ou seja, excluindo da interpretação do texto constitucional as terras ocupadas em épocas anteriores ou aquelas que deixaram de ser ocupadas e venham a sê-las novamente. Por fim, sustenta que a Constituição Federal não assegura o retorno dos indígenas às terras que ocuparam anteriormente à promulgação do texto constitucional ou aos que vieram a ocupar, somente cabendo "o reconhecimento do território que tradicionalmente ocupavam naquele momento" (TRECCANI, ALVES, 2017, p. 587).

Observa-se que a condição exposta na decisão da Petição 3384 com base na tese do marco temporal apresenta clara violação ao direito à titularidade das terras dos povos indígenas, observando-se os fundamentos da sentença da CorteIDH no caso do Povo Xucuru versus Brasil, na jurisprudência da Corte Interamericana que reconhece o direito à propriedade coletiva dos povos indígenas com base no artigo 21 da Convenção Americana de Direitos Humanos, ferindo normas imperativas de direito internacional que estão sob proteção dos tratados de direitos humanos e dos próprios dispositivos constitucionais brasileiros.

Ressalta-se que esta construção judicial, resultado da interpretação dos julgadores, depende da análise das circunstâncias dos casos sobre posse indígena. Porém, não existe legislação atual que estabeleça data determinada como parâmetro ocupação das terras indígenas. Deste modo, nota-se o posicionamento do Professor Doutor Girólamo Treccani (2017, p. 591):

Salienta-se que em nenhum momento a legislação afirma que estas terras deveriam estar ocupadas em determinada data, sendo o dia 5 de outubro de 
1988 um elemento imposto apenas a partir das decisões do STF desde o caso Raposa Serra do Sol que, indevidamente, os ministros do STF, pretendem que irradie seus efeitos para as demais situações semelhantes julgadas posteriormente pela Corte.

É evidente que os povos indígenas, por meio da análise dos fatos histórico-jurídicos, sofrem com o esbulho e com a invasão de suas terras, tendo o STF desconsiderado os estudos antropológicos e as análises periciais da própria FUNAI ao objetivar o marco temporal para a promulgação da Magna Carta de 1988.

Além do âmbito interno, é evidente a violação destes direitos pelo Estado brasileiro, de acordo com a sentença da Corte Interamericana de Direitos Humanos de 5 de fevereiro de 2018. Nesse sentido, o Tribunal declarou o Estado brasileiro internacionalmente responsável pela violação do direito à propriedade coletiva do Povo Indígena Xucuru, interpretado pelo teor do artigo 21 da Convenção Americana de Direitos Humanos.

Explicita-se que o caso Xucuru foi o primeiro a ter sentença do Tribunal Internacional sobre o Brasil por violações a direitos dos povos indígenas. As entidades que provocaram o sistema interamericano de direitos humanos alegaram violações ao direito à propriedade coletiva desse Povo Indígena pela demora no processo de reconhecimento e delimitação das suas terras e territórios ancestrais, bem como pela falta de regularização total desses territórios.

Segundo o Instituto Socioambiental (ISA, 2009), os Xucuru habitam um conjunto de montanhas, conhecidas como Serra de Ororubá, no Estado de Pernambuco, de modo que os registros sobre esses índios datam do século XVI, e desde então sofrem transformações com processos de expropriação de suas terras.

O processo administrativo, apesar de ter garantido a posse tranquila e de ter sido formalmente concluído, apresentou dificuldades para o desejo de ocupantes não indígenas. Ademais, o processo de reconhecimento e de demarcação dessas terras resultou na morte de cinco indígenas, inclusive do chefe do povo Xucuru, conhecido como cacique "Xicão".

Nesse contexto, Girólamo Treccani e Luana Alves (2017, p. 593) expõe, segundo relato da Comissão Nacional da Verdade no caso da Raposa Serra do Sol (apud Maria Rita, 2014), o ocorrido em terras indígenas demarcadas pelo SPI, no Estado do Magro Grosso. Os membros de tribos indígenas Guarani e Kaiowá foram jogados à força em caminhões, vendo suas casas serem queimadas, situação que provocou diversos conflitos internos com vistas à apropriação da terra por não indígenas. Esse foi o método utilizado na colonização para "liberar as terras indígenas" de sua posse.

Releva-se que ministros do Supremo Tribunal Federal já apresentaram posicionamentos favoráveis ao respeito ao direito à propriedade coletiva dos povos indígenas, a exemplo do voto da Ministra Rosa Weber no julgamento da Ação Direta de Inconstitucionalidade 3238 ajuizada pelo Partido Democrata em face do Decreto 4887 de 20 de novembro de 2003, que regulamenta o procedimento para identificação, reconhecimento, delimitação, demarcação e titulação das terras ocupadas por remanescentes das comunidades dos quilombos, objeto do artigo 68 do Ato das Disposições Constitucionais Transitórias da Constituição Federal de 1988.

A ministra abriu a divergência, entendendo pela improcedência do pedido de declaração de inconstitucionalidade do Decreto 4.887/2003. Em sua argumentação, destaca-se o entendimento de que o Estado deve agir positivamente para alcançar o resultado pretendido pela Constituição, seja por medidas legislativas, seja por políticas e programas implementados pelo Executivo, devendo ser apropriados e bem direcionados. Outrossim, a ministra aponta a Convenção 169 da OIT sobre Povos Indígenas e Tribais, de 27 de junho de 1989, devidamente internalizada no ordenamento jurídico brasileiro, destacando que nenhum Estado tem o direito de negar a identidade de um povo indígena ou tribal que se reconheça como tal, demonstrando

Revista de Direito Brasileira | Florianópolis, SC | v. 26 | n. 10 | p. 123-143 | Mai./Ago. 2020 
a explícita contrariedade a tese do marco temporal com base na promulgação da Constituição, sendo que a própria determina a proteção deste grupo minoritário e vulnerável.

Em 2018, nos dias 5 a 12 de novembro de 2018, a Comissão Interamericana fez visita in loco ao Brasil, para observar a situação dos Direitos Humanos no país. Em suas observações, anunciou preocupações e chamou atenção para situações urgentes que exigem das autoridades nacionais e da sociedade em seu conjunto visibilidade, atenção e solução, das quais destacase:

as violações de direitos reiteradas contra as populações indígenas, que sofrem frequentes episódios de violências e desatendimento por serviços públicos, além de enfrentarem dificuldades e obstáculos crescentes para a demarcação de suas terras e dificuldades apresentadas pela tese do marco temporal. (OEA, 2018)

Diante disso, compreende-se que o caso da Raposa Serra do Sol apresenta contexto fático e jurídico para se pleitear demanda perante o Sistema Interamericano de Direitos Humanos diante da escancarada violação ao direito à propriedade coletiva dos povos indígenas e a série de direitos decorrentes de seu uso da terra com a devida demarcação pelo Estado, de modo que as próprias organizações não governamentais são legítimas para provocar a Comissão IDH por meio de petição, configurando, pela análise processual, os requisitos para a apresentação da petição, visto o esgotamento dos recursos internos, a verificação de prazo razoável, levando-se em consideração que a própria Comissão IDH esteve no Brasil por meio de visita in loco e apontou a necessidade de medidas pelas autoridades perante a tese do marco temporal em caráter de recomendação de urgência, conforme o artigo 59, item 8 de seu Regulamento, como verificado no item 18.a do comunicado de imprensa de 12 de novembro de 2018 da Organização dos Estados Americanos e a não existência de litispendência internacional.

Nesse contexto, é possível afirmar que o marco temporal é uma categoria questionável, tendo em vista o modo arbitrário de sua fixação a todos os casos que se referem às terras indígenas. Ademais, como observa Girólamo (2017), em que parte do texto constitucional está expressa a determinação de uma data certa pra a posse indígena? Acredita-se que o artigo 231 não traz qualquer interpretação que leve a tal imposição.

Imprescindível corroborar com as palavras dos autores, como sustenta:

Estabelecer a data de 1988 como: "marco temporal" significa contrariar o princípio da continuidade da proteção constitucional e usurpar os direitos indígenas. O STF em lugar de fazer respeitar os direitos dos índios, conforme determina a Constituição Federal, parece preferir colocar fim aos conflitos entre eles e os usurpadores de suas terras cassando os direitos originários dos povos indígenas. Exigindo que se prove o "renitente esbulho", se utiliza um conceito civilista de "esbulho possessório" absolutamente estranho ao direito constitucional deferido aos índios (TRECCANI, ALVES, 2017, p. 594).

Dessa maneira, é evidente que, diante de todos os casos nacionais e internacionais e de todo o aparato jurídico acerca da proteção dos povos indígenas, o Estado brasileiro falhou em seu dever de proteção aos povos indígenas, apresentando um cenário jurídico extremamente desfavorável após estabelecer a tese do marco temporal como paradigma a partir do julgamento da Petição 3.388-4 de RR. Desde Francisco de Vitória, observa-se o reconhecimento da posse indígena como norma cogente entre os Estados, portanto, devendo 
ser cumprida por toda a comunidade internacional. Por essa razão, o Supremo Tribunal Federal, guardião da Constituição, ao invés de penalizá-los em desrespeito às suas tradições e costumes, deve manter a sua jurisprudência de acordo com a convencionalidade e com a constitucionalidade das normas jurídicas atinentes à questão das terras indígenas.

\section{CONCLUSÃO}

A partir do contato histórico entre os povos europeus com os povos da América, percebe-se uma série de consequências jurídicas, sociais, culturais e ambientais que influenciam a situação dos povos indígenas até os atuais dias. Nesse sentido, os primeiros direitos a serem debatidos no continente europeu apresentaram a necessidade de reconhecimento da dignidade de povos que são diferentes em diversos aspectos do modo de viver europeu.

Essa noção trouxe à ideia de autodeterminação dos povos, de soberania, de relação entre Estados e a inevitabilidade da relação jurídica estabelecida com os povos indígenas. Por essa razão, o direito à propriedade coletiva desses povos, que está intimamente relacionada com o meio ambiente, com a manutenção de valores tradicionais, bem como o fato de tudo isso ter sido construído na terra que cada tribo ocupou, ocupa e ocupará em cada continente.

Todos os povos têm o direito de decidir sobre sua própria vida comunitária, sendo demonstrado exaustivamente que as diferenças devem ser exaltadas de maneira benéfica, ou seja, concedendo espaços para que haja interculturalidade.

A Constituição Federal de 1988 veio ao ordenamento jurídico brasileiro para abranger direitos de toda a sua população, garantindo o direito de posse às comunidades tradicionais em nível igual às populações urbanas e rurais não indígenas. Este é o entendimento encontrado nas declarações de direitos humanos afetas às questões indígenas, em especial à questão da terra dos povos indígenas, afeta à proteção de norma jus cogens, de acordo com os fundamentos teóricos dos estudiosos da Escola Ibérica da Paz, da sentença do caso do Povo Xucuru, da declaração da Comissão IDH perante a tese do marco temporal como preocupação de problema a ser solucionado pelas autoridades competentes, e da própria existência dos povos indígenas nos territórios americanos em tempos anteriores à formação dos Estados, caracterizando norma costumeira de proteção aos direitos dos povos indígenas.

Dito isso, sustenta-se que a Corte Suprema de um país multiétnico, plural e que se afirma teoricamente igualitário, ao proferir a tese do marco temporal, viola evidentemente direitos constitucionais e, que pelo cenário jurídico internacional, ganhou a aceitação da própria comunidade internacional como um todo, ou seja, adquiriu legitimidade como norma a ser seguida pelos Estados que se submetem aos instrumentos jurídicos pertinentes, tais como o Brasil.

Portanto, o marco temporal como tese judicial discricionária, sem o devido amparo legal nas legislações interna e internacional, revela incongruências que violam os direitos que representam a luta de séculos de povos minoritários, partindo de uma Corte Suprema que não somente é guardiã da Constituição, mas que representa o dever do Judiciário brasileiro perante o reconhecimento jurídico e político das heterogêneas identidades étnico-culturais existentes no Brasil. 


\section{REFERÊNCIAS}

BRASIL, Decreto de nº. 591, de 6 de julho de 1992. Pacto Internacional sobre Direitos Econômicos, Sociais e Culturais. Disponível em: http://www.planalto.gov.br/ccivil_03/decreto/1990-1994/d0591.htm. Acesso em: 15 de maio de 2019.

BRASIL, Lei 6.001, de 19 de dezembro de 1973. Lex: dispõe sobre o estatuto do índio. Disponível em: http://www.planalto.gov.br/ccivil_03/LEIS/L6001.htm. Acesso em: 19 de maio de 2019.

BRASIL. Constituição da República Federativa do Brasil, 05 de setembro de 1988. Disponível em: http://www.planalto.gov.br/ccivil_03/constituicao/constituicao.htm. Acesso em: 19 de maio de 2019.

BRASIL. Decreto n ${ }^{\circ}$ 5051, de 19 de abril de 2004. Lex: promulga a convenção 169 da Organização Internacional do Trabalho sobre Povos Indígenas e Tribais, Brasília. Disponível em: http://www.planalto.gov.br/ccivil_03/_ato2004-2006/2004/decreto/d5051.htm. Acesso em: 24 de novembro de 2018.

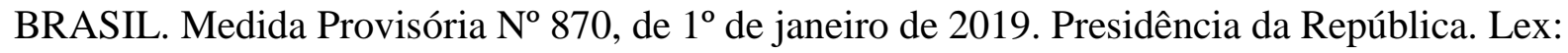
Estabelece a organização básica dos órgãos da Presidência da República e dos Ministérios. Disponível em: http://www.planalto.gov.br/ccivil_03/_ato2019-2022/2019/Mpv/mpv870.htm. Acesso em: 28 de maio de 2019.

BRASIL. Supremo Tribunal Federal. Petição 3.338-4. Relator (a): Min. Ayres Britto, julgado em 19/03/2009. Disponível em:

http://www.stf.jus.br/portal/geral/verPdfPaginado.asp?id=603021\&tipo=AC\&descricao=Inteiro\% 20Teo. Acesso em 10 jan. 2017.

BRASIL. Supremo Tribunal Federal. Petição 3.338-4. Relator (a): Min. Ayres Britto, julgado em 19/03/2009. Disponível em:

<http://www.stf.jus.br/portal/geral/verPdfPaginado.asp?id=603021\&tipo=AC\&descricao=Inteiro \%20Teo>. Acesso em 10 jan. 2017.

CALAFATE, Pedro. A idea de Comunidade Universal em Francisco Suárez. Revista Antiguos Jesuitas en Iberoamérica. Vol. 5, nº 2, págs. 48-65, 2017. Disponível em:

https://dialnet.unirioja.es/servlet/articulo?codigo=6084674. Acesso em: 13 de maio de 2019.

CAMINHA, Pêro Vaz de. Carta a el-rei dom Manuel sobre o achamento do Brasil. Introdução, atualização do texto e notas de M. Viegas Guerreiro. Viegas Guerrerio. Lisboa. Imprensa Nacional- Casa da Moeda, 1974, p. 43-44.

CORTE EUROPEIA DE DIREITOS HUMANOS. Caso Di Sarno e outro vs. Itália, nº 30765/08 Sentença de 7 de outubro de 2012. https://hudoc.echr.coe.int/eng\#\{\%22itemid\%22:[\%22001$108480 \% 22\rceil\}$

CORTE INTERAMERICANA DE DIREITOS HUMANOS (Corte IDH). Caso da Comunidade Moiwana vs. Suriname. Mérito, Reparações e Custas. Sentença de 15 de junho de 2005c. Disponível em: http://www.corteidh.or.cr/docs/casos/articulos/seriec_124_ing.pdf. Acesso em: 13 de maio de 2019. 
CORTE INTERAMERICANA DE DIREITOS HUMANOS. Opinião no 23/17. Opinião consultiva sobre as obrigações dos Estados em relação ao meio ambiente no âmbito da proteção e garantia dos direitos à vida e à integridade pessoal. Parecer de 15 de novembro de 2017.

DEUTSCHE WELLE. Notícias. 17 de maio de 2019. Disponível em: https://p.dw.com/p/3IgB8. Acesso em: 28 de maio de 2019.

Autor. O desenvolvimento das normas jus cogens em relação ao reconhecimento do direito à propriedade coletiva dos povos indígenas à luz da sentença do caso Povo Indígena Xucuru e seus membros versus Brasil. Revista da Faculdade de Direito UFPR, Curitiba, PR, Brasil, v. 64, n. 1, p. 9 -38, jan./abr. 2019. ISSN 2236-7284. Disponível em:

https://revistas.ufpr.br/direito/article/view/61647. Acesso em: 30 abr. 2019.

FILHO, Carlos Frederico Marés de Souza. O Renascer dos Povos Indígenas para o Direito. $1^{\text {a }}$

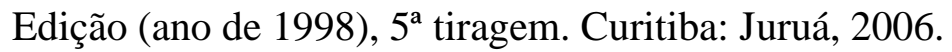

GIAROLA, Flavio Raimundo. O Povo Novo Brasileiro: mestiçagem e identidade no pensamento de Darcy Ribeiro. Revista do Programa de Pós-graduação em História, Universidade do Estado de Santa Catarina, v.4, n. 1, p. 126-140. Disponível em:

http://www.revistas.udesc.br/index.php/tempo/article/view/2175180304012012127. Acesso em: 19 de maio de 2019.

GRUPO DE TRABALHOS INTERNACIONAIS PARA ASSUNTOS INDÍGENAS. The Indigenous World 2015. Edição de Cæcillie Mikkelsen. Eks-Skolen Trykkeri: Copenhague, Dinamarca, 2015.

INSTITUTO SÓCIO AMBIENTAL. FIALHO, Vânia, M. NEVES, Rita de Cássia. Povos Indígenas em Pernambuco. Povo Xukuru. Setembro de 2009. Disponível em: https://pib.socioambiental.org/pt/Povo:Ikpeng. Acesso em: 29 de maio de 2019.

INSTITUTO SÓCIO AMBIENTAL. GUIRARDELLO, Raquel. Parque Indígena do Xingu. Povos Indígenas no Mato Grosso. Povo Trumai. Dezembro de 2002. Disponível em: https://pib.socioambiental.org/pt/Povo:Trumai. Acesso em: 29 de maio de 2019.

INSTITUTO SÓCIO AMBIENTAL. MENGET, Patrick, TRONCARELLI, Maria Cristina. Parque Indígena do Xingu. Povos Indígenas do Mato Grosso. Disponível em: https://pib.socioambiental.org/pt/Povo:Ikpeng. Acesso em 29 de maio de 2019.

INSTITUTO SÓCIO AMBIENTAL. Políticas Indigenistas. Disponível em: https://pib.socioambiental.org/pt/\%C3\%93rg\%C3\%A3o_Indigenista_Oficial. Acesso em: 29 de maio de 2019.

INSTITUTO SÓCIO AMBIENTAL. SENRA, Klinton. Parque Indígena do Xingu. Povos Indígena no Mato Grosso. Povo Kaiabi. Março de 1999. Disponível em: https://pib.socioambiental.org/pt/Povo:Kaiabi. Acesso em: 29 de maio de 2019.

INSTITUTO SOCIOAMBIENTAL. Programa Povos Indígenas no Brasil. Quantos são? Disponível em: https://pib.socioambiental.org/pt/Quantos_s\%C3\%A3o\%3F. Acesso em: 19 de maio de 2019.

INTERNATIONAL WORK GROUP FOR INDIGENOUS AFFAIRS. The Indigenous World 2015. Dinamarca, Copenhague: Edição de Cæcilie Mikkelsen, abril de 2015. Disponível em: 
https://www.iwgia.org/images/publications/0716_THE_INDIGENOUS_ORLD_2015_eb.pdf. Acesso em: 29 de maio de 2019.

MONTES D'OCA, Fernando Rodrigues. O direito positivo das gentes e a fundamentação não naturalista da escravidão em Francisco de Vitória. Revista Mediaevalia. Textos e Estudos. Faculdade de Letras da Universidade de Porto. v. 31, p. 29-50, 2012. Disponível em: http://ojs.letras.up.pt/index.php/mediaevalia/article/view/813. Acesso em: 29 de maio de 2019.

MONTES D'OCA, Fernando Rodrigues. Política, Direito e Relações Internacionais em Francisco de Vitória. Revista Opinião Filosófica, [S.1.], v. 3, n. 1, fev. 2017. ISSN 2178-1176. Disponível em: http://periodico.abavaresco.com.br/index.php/opiniaofilosofica/article/view/447. Acesso em: 07 set. 2018.

OLIVEIRA, Oris. Contribuição de Francisco de Vitoria ao Direito Internacional Público no de "Indis Recenter Inventis, Relectio Prior". Revista da Faculdade de Direito da Universidade de São Paulo. v. 68, n. 2, p. 361-384, São Paulo, 1973. Disponível em: https://doi.org/10.11606/issn.2318-8235.v68i2p361-384. Acesso em: 28 de agosto de 2018.

ORGANIZAÇÃO DOS ESTADOS AMERICANOS. Comunicados de Imprensa. 2018. Disponível em: < https://www.oas.org/pt/cidh/prensa/notas/2018/238.asp >. Acesso em: 09 de maio de 2019.

ORGANIZAÇÃO DOS ESTADOS AMERICANOS. Comunicados de Imprensa. No 238 de 2018. Disponível em: https://www.oas.org/pt/cidh/prensa/notas/2018/238.asp. Acesso em: 29 de maio de 2019.

PERRONE-MOISÉS, Beatriz. Terras Indígenas na Legislação Colonial. Revista da Faculdade de Direito, Universidade de São Paulo, v. 95, p. 107-120, 2000. Disponível em: http://www.revistas.usp.br/rfdusp/article/view/67457/70067. Acesso em: 02 de maio de 2019.

RIBEIRO, Darcy. Os índios e a civilização: a integração das populações indígenas no brasil moderno. $7^{a}$ edição brasileira. São Paulo: companhia das Letras, 1996.

SALUSTINO, Felipe Henrique Cadó. BARTOLOMÉ DE LAS CASAS: à procura de igualdade e justiça aos homens (1550-1552). Natal, Rio Grande do Norte, Editor História, 2013. Disponível em: https://monografias.ufrn.br/jspui/handle/1/701. Acesso em: 03 de maio de 2019.

SCHELL, Deise Cristina. Os Índios na Conquista Espanhola da América: Leyes Nuevas e Representações à Época da Jornada de Omagua e Dorado. Revista de História, v. 2, n. 1, p. 2238, 2010.

SILVEIRA LOUREIRO, Silvia Maria da. O domínio dos povos indígenas do novo mundo segundo a concepção da escola ibérica da paz (séculos XVI e XVII). Revista do Instituto Brasileiro de Direitos Humanos. n. 15, p. 335-350, dez. 2015. Disponível em: http://revista.ibdh.org.br/index.php/ibdh/article/view/322. Acesso em: 13 de maio de 2019.

TRECCANI, Girolamo, ALVES, Luana. Os direitos territoriais indígenas e a (in)compatibilidade com o marco temporal. In: BATOS, E., FONSECA, L., BLAGITZ, Patrícia (Coord.). Direitos Humanos na Amazônia. Salvador: Editora Juspodvim, 2017. 
TRIBUNAL EUROPEU DOS DIREITOS DO HOMEM. Convenção Europeia dos Direitos do Homem. Concelho da Europa. Roma, 4 de novembro de 1950. Disponível em: https://www.echr.coe.int/Documents/Convention_POR.pdf. Acesso em: 27 de maio de 2019.

TRINDADE, Antônio Augusto Cançado. Direitos humanos e meio ambiente: Paralelo dos sistemas de proteção internacional. Porto Alegre: Sérgio Fabris, 1993.

TRINDADE, Cançado. Direitos Humanos e Meio Ambiente. Fortaleza: Expressão Gráfica e Editora, 2017.

TRINDADE, Cançado. Prefácio: a visão universalista e humanista do direito das gentes e atualidade da obra de Francisco de Vitoria. In: Relectiones: sobre os índios e sobre o poder civil. Organização e apresentação por José Carlos Brandi Aleixo. Brasília: Editora Universidade de Brasília, 2016.

UNIVERSIDADE DE SÃO PAULO. Biblioteca Virtual de Direitos Humanos. Declaração sobre o direito ao desenvolvimento das Nações Unidas de 4 de dezembro de 1986. Disponível em: http://www.direitoshumanos.usp.br/index.php/direito-ao-desenvolvimento/declaracao-sobre-odireito-ao-desenvolvimento.html. Acesso em: 16 de maio de 2019.

VITORIA, Francisco de. Relectiones: sobre os índios e sobre o poder civil. Organização e apresentação por José Carlos Brandi Aleixo. Brasília: Editora Universidade de Brasília, 2016.

VITÓRIA, Francisco de. Sobre o poder civil, os índios e a Guerra. Edição de Renan Santos. Porto Alegre, Rio Grande do Sul: Concreta, 2017. 